\title{
Self-Collected Samples in Cervical Cancer Screening: Results of HPV and Pap Self-Collected Samples Compared to Physician-Obtained Specimens
}

\author{
Bernhard Reinhold Mangold \\ Zytolabor Ludwigsburg, Ludwigsburg, Germany
}

\author{
Keywords \\ Cervical cancer · Screening · Self-collected samples · HPV • \\ Pap test
}

\begin{abstract}
Objective: In order to increase overall participation in cervical cancer screening, several investigators propose a concept of introducing self-tests. The study presented here compared test results of the Pap test and 4 different HPV test systems of self-collected and physician-collected vaginal specimens. Study Design: 208 patients of a colposcopy clinic had physician-taken and self-taken vaginal samples. All cell samples enabled a liquid-based Pap test and testing for carcinogenic HPV genotypes. In addition, all patients had a colposcopy with or without cervical biopsy and/or conisation. Results: 99 patients had the histological diagnosis of $\mathrm{CIN2+}$. The HPV test sensitivity of self-collected samples differed significantly in this patient group depending on the test system performed. The sensitivity of the self-collected Pap test was significantly lower than HPV testing, but the positive predictive value of the Pap self-test was very high. Conclusion: The results of this study indicate that under the circumstances of self-testing HPV test systems differ in test
\end{abstract}

\begin{tabular}{ll}
\hline KARGER & ( 2019 The Author(s) \\
Published by S. Karger AG, Basel & Karger \\
E-Mail karger@karger.com & $\begin{array}{l}\text { This article is licensed under the Creative Commons Attribution- } \\
\text { NonCommercial-NoDerivatives 4.0 International License (CC BY- } \\
\text { www.karger.com/acy }\end{array}$ \\
$\begin{array}{l}\text { NC-ND) (http://www.karger.com/Services/OpenAccessLicense). } \\
\text { Usage and distribution for commercial purposes as well as any dis- } \\
\text { tribution of modified material requires written permission. }\end{array}$
\end{tabular}

sensitivity and specificity. Self-collected Pap tests can provide a test result with a very high positive predictive value and introduce therapeutic strategies. In order to improve screening strategies, it could be an opportunity to combine HPV and Pap tests in self-taken vaginal samples, especially in countries with a low income level. In countries with a good medical infrastructure, self-testing has to be introduced with caution.

(C) 2019 The Author(s) Published by S. Karger AG, Basel

\section{Introduction}

The discovery of the interrelation of HPV infections and carcinomas of the cervix together with the availability of standardized HPV tests has led to intense discussions about future cervical cancer screening strategies [13]. A number of established screening programs have already been supplemented with HPV testing, while in others the primary screening will be changed from cytologically based Pap testing to HPV testing [4-7].

Experts agree that the rate of participation plays a very important role in screening programs. Recent investigations have shown that the highest rate of cervical cancer 
is found in the group of nonattenders $[8,9]$. Therefore, in order to improve prevention strategies, several aspects of program organization have to be taken into account. For this purpose, invitation programs already exist in some countries [10]. Another suggestion is to implement modalities for the self-collection of samples [11-15]. A number of studies have demonstrated that HPV self-tests have a high sensitivity in the diagnosis of cervical (pre)cancer [16-18].

Even though the offer of the self-collection might motivate some people to participate in the screening program, the influence is limited. Some reasons for nonattendance, like anxiety about a cancer diagnosis, cannot be eliminated by self-collection of samples [19]. Furthermore, in case of a positive HPV test, the patients need a follow-up which is not possible without the direct contact to the practitioner. Sample self-collection raises the participant rate eventually only in the first step of the clinical diagnostic cascade.

This problem is tightened by the fact that HPV tests are very sensitive and detect also viral infections which will not require any treatment [20]. The low rate of the development of (pre)cancer may prevent patients with reservations to visit a practitioner also if they have a positive HPV test result. In addition, in some patients, it was even shown that the HPV infection of their vulva, vagina, and cervix differed in type and rate $[21,22]$. This necessitates an exact sampling technique which is not possible with a self-sampling device $[23,24]$.

To further investigate the influence of the sample-taking method, this study compared results of self-collected and clinician-collected specimens. Samples of 208 patients from a colposcopy clinic were taken both by a clinician and by the women themselves. All cell samples were tested using different HPV tests and the cytological Pap test.

\section{Materials and Methods}

Attendees of a colposcopy clinic bear a high risk of having abnormal conditions of the cervix. After informed consent, 208 patients agreed to perform self-collection of a sample before their clinical investigation. The women were asked to insert a specially developed swab (Rovers ${ }^{\circledR}$ Viba-Brush) deep into their vagina without touching the labia. The swab was then diluted into fluid (PreservCyt ${ }^{\circledR}$-Solution, Hologic) by a nurse. This procedure was followed by the investigation of the clinician. Under visual control (specula), the clinician collected cells from the cervix with a Rovers ${ }^{\circledR}$ Cervex-Brush with immediate dilution into PreservCyt ${ }^{\circledR}$. This was followed by a colposcopy with iodine and acetic acid testing. If indicated, punch biopsies (PB) of the cervix were taken with
Table 1. Test results

\begin{tabular}{|c|c|c|}
\hline & Self-test & Clinician-taken tes \\
\hline PAP test $\left(\right.$ ThinPrep $\left.{ }^{\circledR}\right)$ & 208 & 208 \\
\hline Punch biopsy & & 183 \\
\hline Cone biopsy & & 84 \\
\hline \multicolumn{3}{|l|}{$\mathrm{HPV}$} \\
\hline Cervista $^{\circledR}$ & 208 & 208 \\
\hline Linear Array ${ }^{\circledR}$ & 106 & 106 \\
\hline Aptima $^{\circledR}$ & 106 & 106 \\
\hline EUROArray $^{\circledR}$ & 106 & 106 \\
\hline
\end{tabular}

Tischler-Morgan biopsy forceps. In some patients, a cone biopsy (CB) was performed after an interval, as a cold knife $\mathrm{CB}$, a laser $\mathrm{CB}$, or a large loop excision of the transformation zone.

All histological diagnoses of $\mathrm{PB}$ were evaluated in the same pathology laboratory. The histological diagnoses of CB specimens were evaluated independently in different pathology laboratories. Histological classification of intraepithelial neoplasia followed the WHO guidelines (WHO 2003; CIN1-3) in all cases [25].

From all self- and clinician-taken cell samples, a liquid-based cytology specimen (ThinPrep ${ }^{\circledR} 2000$ Prozessor; Hologic Inc., San Diego, CA, USA) was produced. This was followed by different HPV tests (Table 1). In a first group of 102 patients, a simple target hybridization (non-NAAT)-based method was used, followed by signal amplification (Cervista ${ }^{\circledR} ;$ Hologic). The Cervista test targets the HPV gene regions L1/E6/E7 and offers qualitative detection of DNA from 14 high-risk (hr) HPV types. It cannot determine the underlying specific HPV type. In a second group of 106 patients, Cervista together with 3 other HPV tests based on target amplification (NAAT) were performed. The first was the Linear Array ${ }^{\circledR}$ HPV genotyping test (Roche Diagnostics GmbH, Mannheim, Germany). The Linear Array test is a qualitative PCR-based method (target region L1) which detects, in a type-specific manner, the DNA of $37 \mathrm{hr}$ - and low-risk (lr)-HPV types. The second was the Aptima ${ }^{\circledR}$ HPV test (Hologic Inc.). The Aptima test is a transcription-mediated amplification-based method (target region E6/E7) for the qualitative detection of E6/E7 mRNA from $14 \mathrm{hr}-\mathrm{HPV}$ types. This test cannot determine the underlying specific HPV type. And the third was the EUROArray HPV (Euroimmun AG, Lübeck, Germany). The EUROArray HPV is a qualitative PCRbased method (target region E6/E7) which detects, in a type-specific manner, the DNA of $30 \mathrm{hr}$ - and lr-HPV types. Based on the publication of Muňoz et al. [26] the detection of one or more of the 18 prescribed hr- and probable-hr-HPV types was counted as a HPV-hr-positive result.

The liquid-based cytology slides of 206 patients were screened and interpreted according to the nomenclature of Munich 2 and 3 used in Germany. The slides of the first 102 patients were interpreted by 2 cytologists independently, one cytologist was completely blinded. The nomenclature of Munich 2 and 3 was transformed into Bethesda criteria in the following manner: Munich group $\mathrm{I} / \mathrm{II}=$ Bethesda negative, Munich group IIID/IIID1 = Bethesda LSIL, Munich group III = Bethesda ASCUS, Munich group IID2/IVa/IVb = Bethesda HSIL. 
Fig. 1. HPV-hr test negativity in 106 patients with 4 different HPV tests.
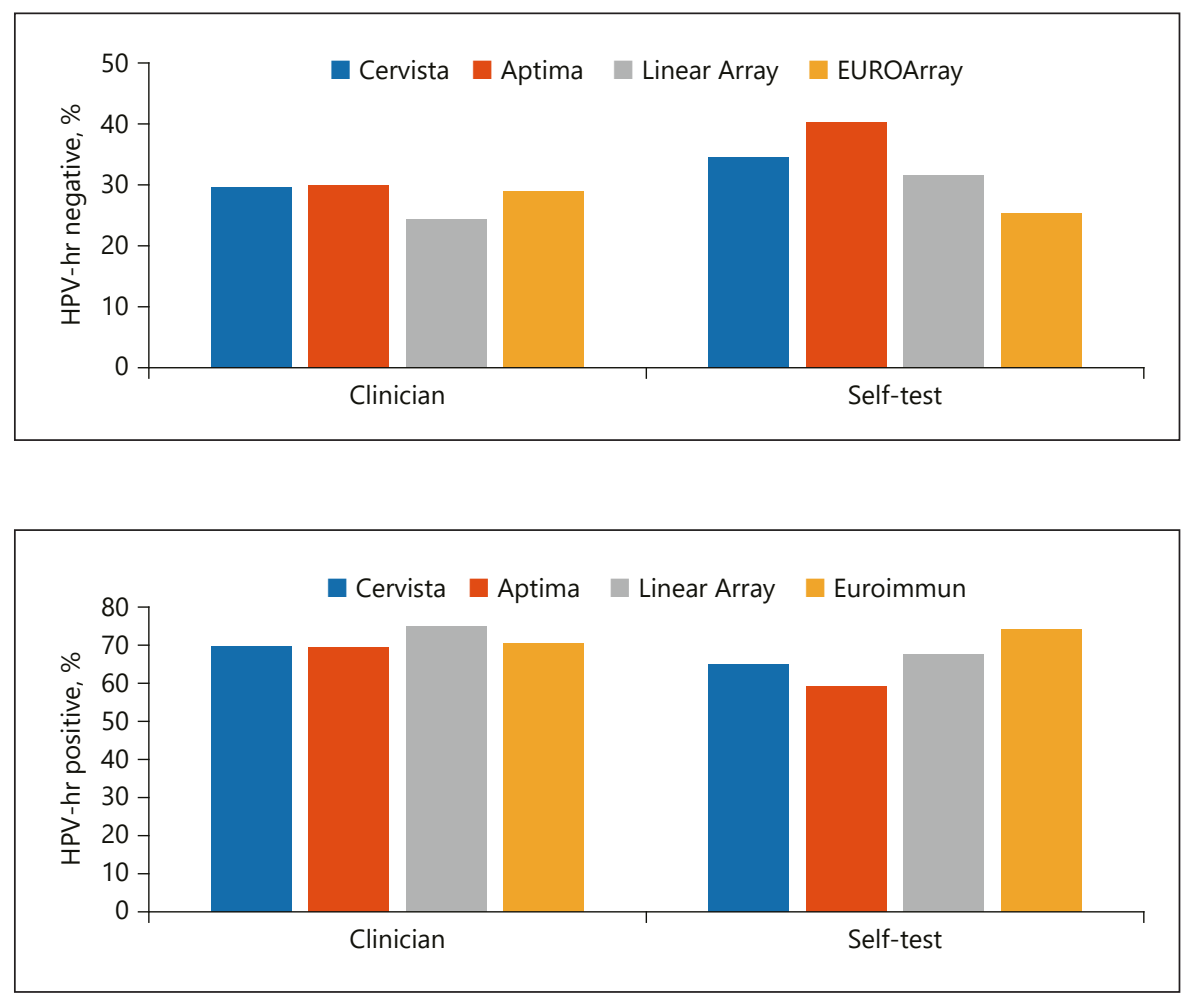

Fig. 2. HPV-hr test positivity in 106 patients with 4 different HPV tests. in the clinician-taken test samples. Differences between test positivity (HPV-hr) and test negativity were higher in the self-test group (Fig. 1, 2). In clinician-taken test samples, there was a complete concordance of the $4 \mathrm{HPV}-\mathrm{hr}$ test results in 83 of 106 patients (78\%). In the self-test samples, a concordance of the 4 test results was only found in 72 patients $(68 \%)$.

There were also differences in test results between selfand clinician-taken test samples within the test systems. The highest rate of discordance between self- and clinician-taken test (HPV-hr positive/negative) was found in Aptima (14\%). Euroimmun and Cervista had a discordance rate of 10 and $9 \%$; the lowest rate of discordance was found in the Linear Array with 7\%. The PCR-based test systems of Roche and Euroimmun allowed a comparison of test results not only in respect of HPV-hr/lr positivity but also in a type-specific manner. The Linear Array showed a discordance of HPV-hr types in self- and clinician-taken test samples in 20 cases (19\%); under consideration of $\mathrm{hr}$ and lr types, the rate increased to $26 \%$. The Euroimmun showed a discordance of HPV-hr types in 32 cases (30\%); under consideration of hr and lr types, the rate increased to $47 \%$.

A histological diagnosis of CIN2+ (PB and/or CB) had 99 of the 208 patients. The test sensitivity of the performed 
Fig. 3. Differences between HPV-hr test positivity in 99 patients with CIN2+.
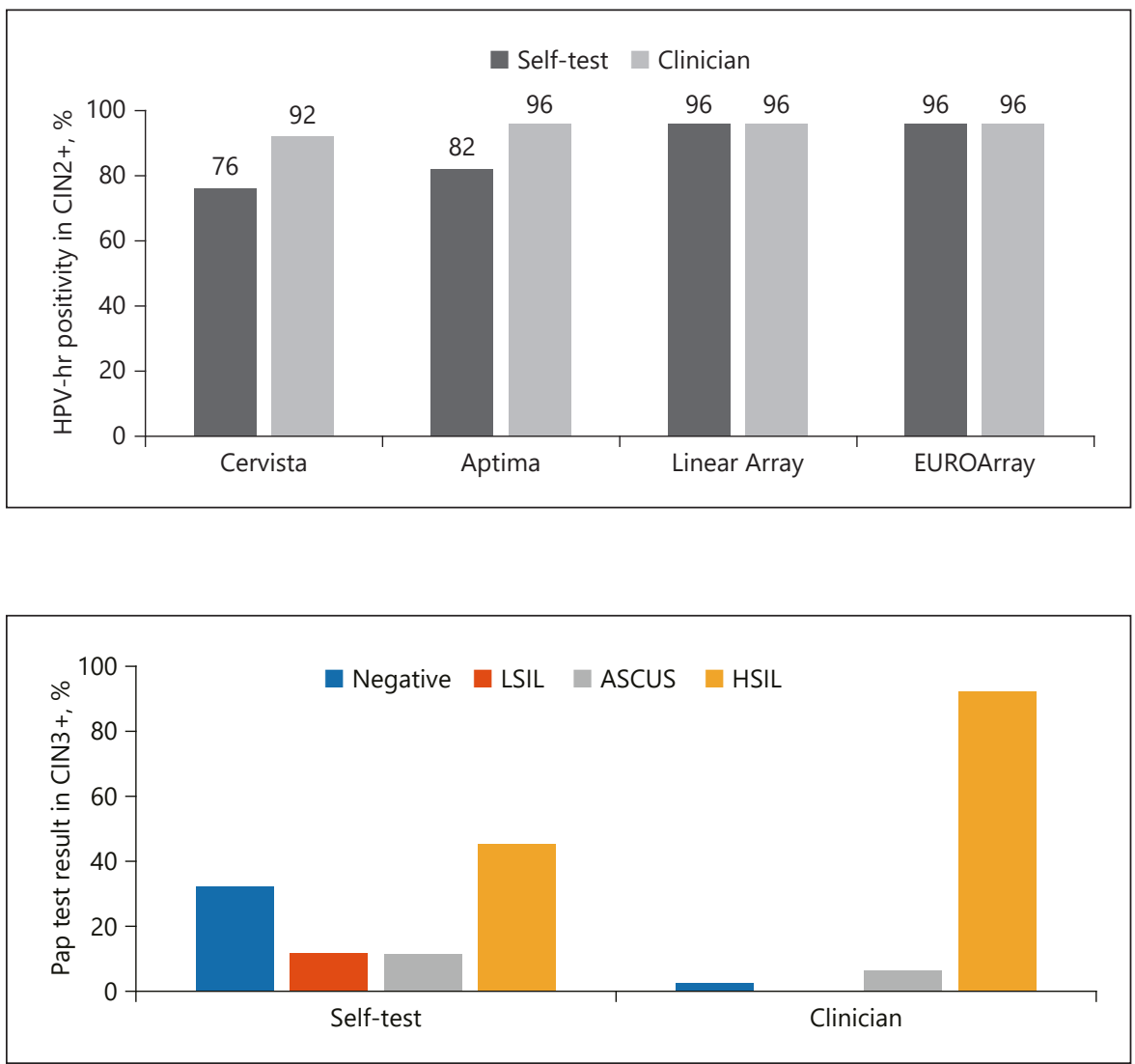

Fig. 4. Pap test result in 47 patients with $\mathrm{CIN} 3+$ (PB and $\mathrm{CB}, 1$ invasive cancer).

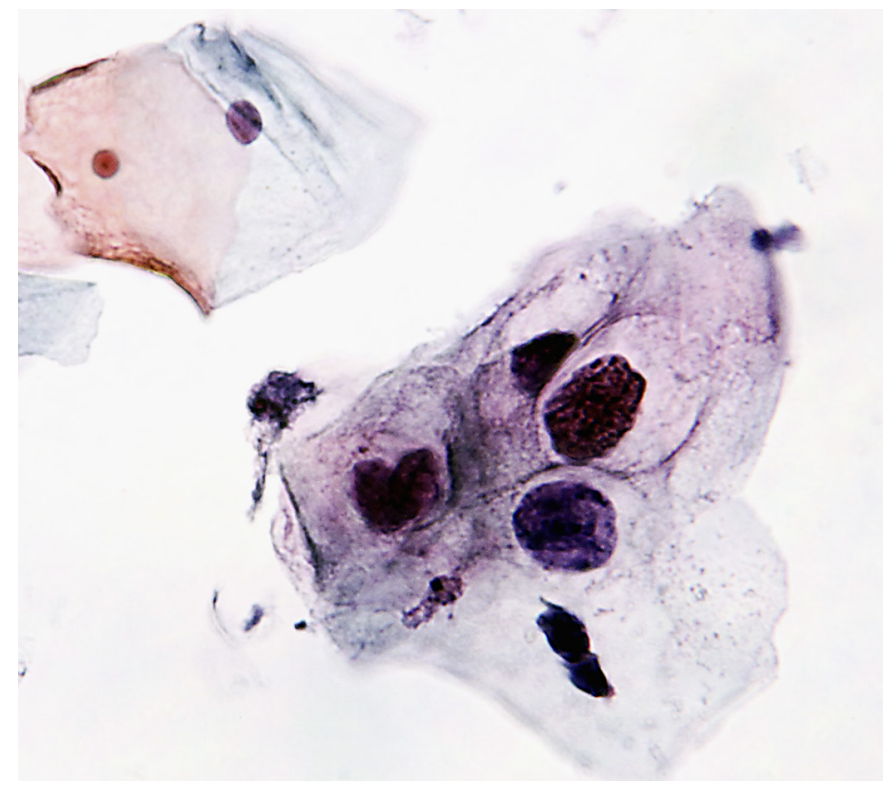

Fig. 5. Pap self-test: LSIL.
HPV tests differed in this patient group significantly. Cervista and Aptima had in self-test samples a lower sensitivity than in clinician test samples (Cervista self-test sensitivity: 76\%, clinician test: 92\%; Aptima self-test sensitivity: 82\%, clinician test: 96\%). The Linear Array and Euroimmun tests had altogether a higher sensitivity and did not show a difference between self-test and clinician test samples with an overall sensitivity of $96 \%$ (Fig. 3 ).

\section{Cytology}

The overall Pap test results of the two different cytologists (102 patients) showed a concordance of test results (negative versus LSIL/ASCUS/HSIL) in the clinician test samples of $92 \%$ and in the self-test samples of $85 \%$. A very high rate of concordance was found in the clinician test samples of patients with the histological diagnosis of CIN2+ (50 patients) with $98 \%$.

The rate of abnormal Pap test results in all patient (208 patients) was in the clinician test samples $28 \%$ higher than in the self-test samples ( 73 vs. $45 \%$ ). In the group of patients with the histological diagnosis of CIN3+ in PB and $\mathrm{CB}$ (47 patients), the concordance of the Pap test re- 


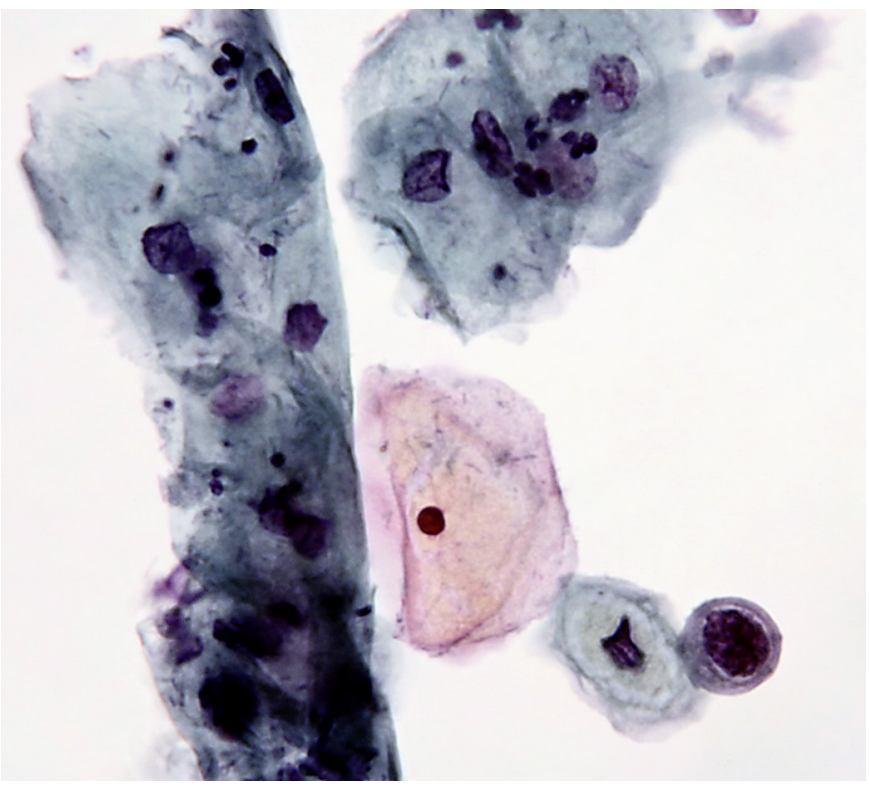

Fig. 6. Pap self-test: HSIL.

sult of the clinician test samples and histology was very high (91\% HSIL). Even in the self-test sample group there was a concordance between cytology and histology of $45 \%$ HSIL. In addition, $23 \%$ of these self-test samples were diagnosed as LSIL or ASCUS (Fig. 4).

\section{Discussion}

The impact of the sampling technique differed between the test modalities investigated. Regarding test sensitivity, the highest difference between self and clinician testing was found in Pap tests (45 vs. 91\% HSIL in the detection of CIN3+). It is well known that Pap test sensitivity varies dramatically, and this result emphasizes once more the importance of an optimal sampling technique in cytological screening.

The effect of the sampling technique on HPV test sensitivity depends on the test system. Cervista and Aptima (Hologic) showed a significant difference between self and clinician testing in this investigation. The PCR-based Linear Array (Roche) and Microarray (Euroimmun) did not show a difference in test sensitivity, even though the comparison of HPV-type-specific test results (lr and/or hr) showed a difference up to $47 \%$. Especially in healthy persons without (pre)cancer this is a problem, because test specificity will be lowered. Therefore, in a screening

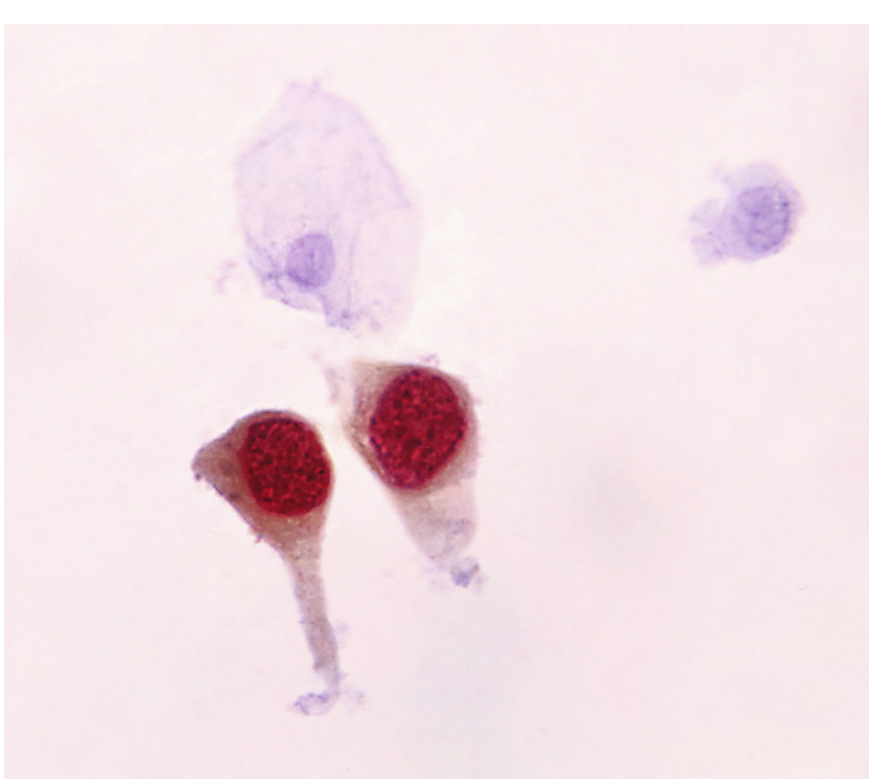

Fig. 7. Self-test immunocytology (p16/Ki67 CINtec plus $\left.{ }^{\circledR}\right)$ : positive.

based on HPV self-testing, several facts have to be taken into account. The sensitivity depends on the test system and reaches not in all test systems the sensitivity of clinician testing. On the other hand, highly sensitive test systems demand special skills in the technique of self-sampling [27]. An uncontrolled sampling technique (e.g., at home or with a vaginal lavage) bears the risk of measuring HPV infections not correlated to the cervix uteri and interacts negatively with test specificity.

Beside the aspects of different test systems and sampling techniques, the question of how to motivate patients for self-sampling arises. Just mailing sampling devices to patients will not be sufficient. However, advertising self-sampling bears the risk to influence negatively the habits of visiting a gynecologist. Alternatively, primary care providers could detect nonattenders and provide self-sampling devices under control. Older patients in particular neglect cervical cancer screening but visit physicians because of other health problems.

Finally, we need a strategy to manage patients with a positive HPV-hr self-test result. A useful method to increase the positive predictive value of the method would be to perform a Pap test within the available self-test samples (Fig. 5-7); 45\% of patients with the diagnosis of CIN3+ had in this investigation a HSIL result in Pap selftesting. All patients with a HSIL result in Pap self-testing had the diagnosis of CIN2+. 


\section{Acknowledgment}

I would like to thank Prof. Dr. H. F. Nauth (FIAC/Stuttgart), Dr. Cavalar (Euroimmun/Lübeck), and Dr. Schalasta (Labor Enders/Stuttgart) for their support in collecting data and discussing the results.

\section{Statement of Ethics}

The patients have given their informed consent.

\section{Disclosure Statement}

The author has no financial disclosure.

\section{Funding Sources}

This publication has no financial support.

\section{References}

1 Dürst M, Gissmann L, Ikenberg H, zur Hausen H. A papillomavirus DNA from a cervical carcinoma and its prevalence in cancer biopsy samples from different geographic regions. Proc Natl Acad Sci USA. 1983 Jun;80(12):3812-5.

2 Kitchener H. HPV testing alone is not as safe as cytology and selective HPV testing AGAINST: there is powerful evidence for primary cervical screening. BJOG. 2016 Jan;123(1):68.

3 Wentzensen N, Schiffman M, Palmer T, Arbyn M. Triage of HPV positive women in cervical cancer screening. J Clin Virol. 2016 Mar; 76 Suppl 1:S49-S55.

4 Meijer CJ, Berkhof J, Castle PE, Hesselink AT, Franco EL, Ronco G, et al. Guidelines for human papillomavirus DNA test requirements for primary cervical cancer screening in women 30 years and older. Int J Cancer. 2009 Feb; 124(3):516-20.

5 Saville AM. Cervical cancer prevention in Australia: Planning for the future. Cancer $\mathrm{Cy}$ topathol. 2016 Apr;124(4):235-40.

6 Gemeinsamer Bundesausschuss: Richtlinie für organisierte Krebsfrüherkennungsprogramme und Krebsfrüherkennungs-Richtlinie: Programm zur Früherkennung von Zervixkarzinomen, Beschlussdatum: 22.11.2018. Available from: https://www.g-ba.de/informationen/beschluesse/3597/.

7 Polman NJ, Snijders PJ, Kenter GG, Berkhof J, Meijer CJ. HPV-based cervical screening: Rationale, expectations and future perspectives of the new Dutch screening programme. Prev Med. 2019 Feb;119:108-17.

8 Marquardt K, Büttner $\mathrm{HH}$, Broschewitz $\mathrm{U}$, Barten M, Schneider V. Persistent carcinoma in cervical cancer screening: non-participation is the most significant cause. Acta Cytol. 2011;55(5):433-7.

9 Bos AB, Rebolj M, Habbema JD, van Ballegooijen M. Nonattendance is still the main limitation for the effectiveness of screening for cervical cancer in the Netherlands. Int J Cancer. 2006 Nov;119(10):2372-5.

10 Wentzensen N, Arbyn M, Berkhof J, Bower M, Canfell K, Einstein M, et al. Eurogin 2016 Roadmap: how HPV knowledge is changing screening practice. Int J Cancer. 2017 May; 140(10):2192-200.
11 Castle PE, Rausa A, Walls T, Gravitt PE, Partridge EE, Olivo V, et al. Comparative community outreach to increase cervical cancer screening in the Mississippi Delta. Prev Med. 2011 Jun;52(6):452-5.

12 Petignat P, Vassilakos P. Is it time to introduce HPV self-sampling for primary cervical cancer screening? J Natl Cancer Inst. 2012 Feb;104(3):166-7.

13 Zhao FH, Lewkowitz AK, Chen F, Lin MJ, Hu SY, Zhang X, et al. Pooled analysis of a selfsampling HPV DNA Test as a cervical cancer primary screening method. J Natl Cancer Inst. 2012 Feb;104(3):178-88.

14 Virtanen A, Nieminen P, Luostarinen T, Anttila A. Self-sample HPV tests as an intervention for nonattendees of cervical cancer screening in Finland: a randomized trial. Cancer Epidemiol Biomarkers Prev. 2011 Sep;20(9):1960-9.

15 Verdoodt F, Jentschke M, Hillemanns P, Racey CS, Snijders PJ, Arbyn M. Reaching women who do not participate in the regular cervical cancer screening programme by offering self-sampling kits: a systematic review and meta-analysis of randomised trials. Eur J Cancer. 2015 Nov;51(16):2375-85

16 Wright TC Jr, Denny L, Kuhn L, Pollack A, Lorincz A. HPV DNA testing of self-collected vaginal samples compared with cytologic screening to detect cervical cancer. JAMA. 2000 Jan;283(1):81-6.

17 Petignat P, Faltin DL, Bruchim I, Tramèr MR, Franco EL, Coutlée F. Are self-collected samples comparable to physician-collected cervical specimens for human papillomavirus DNA testing? A systematic review and meta-analysis. Gynecol Oncol. 2007 May;105(2):530-5.

18 Gök M, Heideman DA, van Kemenade FJ, Berkhof J, Rozendaal L, Spruyt JW, et al. HPV testing on self collected cervicovaginal lavage specimens as screening method for women who do not attend cervical screening: cohort study. BMJ. 2010 Mar;340:c1040.

19 Zeissig SR, Radde K, Kaiser M, Blettner M, Klug SJ. [Quality assurance in an epidemiological cohort study: on-site monitoring in gynaecological practices]. Z Evid Fortbild Qual Gesundhwes. 2014;108(8-9):517-27. German.
20 Petry KU, Luyten A, Justus A, Iftner A, Strehlke S, Reinecke-Lüthge A, et al. Prevalence of high-risk HPV types and associated genital diseases in women born in 1988/89 or 1983/84 - results of WOLVES, a populationbased epidemiological study in Wolfsburg, Germany. BMC Infect Dis. 2013 Mar;13(1): 135

21 Cañadas MP, Bosch FX, Junquera ML, Ejarque $\mathrm{M}$, Font R, Ordoñez E, et al. Concordance of prevalence of human papillomavirus DNA in anogenital and oral infections in a high-risk population. J Clin Microbiol. 2004 Mar;42(3): $1330-2$.

22 Rumbold AR, Tan SE, Condon JR, TaylorThomson D, Nickels M, Tabrizi SN, et al. Investigating a cluster of vulvar cancer in young women: a cross-sectional study of genital human papillomavirus prevalence. BMC Infect Dis. 2012 Oct;12(1):243.

23 Harper DM, Longacre MR, Noll WW, Belloni DR, Cole BF. Factors affecting the detection rate of human papillomavirus. Ann Fam Med. 2003 Nov-Dec;1(4):221-7.

24 de Melo Kuil L, Lorenzi AT, Stein MD, Resende JC, Antoniazzi M, Longatto-Filho A, et al. The Role of Self-Collection by Vaginal Lavage for the Detection of HPV and HighGrade Intraepithelial Neoplasia. Acta Cytol. 2017;61(6):425-33

25 Tavassoli FA, Devilee P. Pathology \& Genetics. Tumours of the Breast and Female Genital Organs. World Health Organization Classification of Tumours. Lyon: IARC Press; 2003.

26 Muñoz N, Bosch FX, de Sanjosé S, Herrero R, Castellsagué $\mathrm{X}$, Shah $\mathrm{KV}$, et al; International Agency for Research on Cancer Multicenter Cervical Cancer Study Group. Epidemiologic classification of human papillomavirus types associated with cervical cancer. N Engl J Med. 2003 Feb;348(6):518-27.

27 Belinson JL, Hu S, Niyazi M, Pretorius RG Wang H, Wen C, et al. Prevalence of type-specific human papillomavirus in endocervical, upper and lower vaginal, perineal and vaginal self-collected specimens: implications for vaginal self-collection. Int J Cancer. 2010 Sep; 127(5):1151-7. 